\title{
Prevalence of Tobacco Consumption, Alcohol, Khat (Catha Edulis) Use and High Blood Pressure among Adults In Jimma Town, South West Ethiopia
}

\author{
Sisay Bissa Jima ${ }^{1}$, Tomas Benti Tefera ${ }^{2,}$, , Muktar Beshir Ahmed ${ }^{2}$ \\ ${ }^{1}$ Department of Biomedical Sciences, Arsi University, College of Medicine and Health Sciences, Assella Town, Southeast Ethiopia \\ ${ }^{2}$ Department of Nursing, Madawalabu University, College of Medicine and Health Sciences, Bale-Goba, Southeast Ethiopia
}

Email address:

sababona@yahoo.com (S. B. Jima), thomas_benti@yahoo.com (T. B. Tefera), muktarbeshir@yahoo.com (M. B. Ahmed)

\section{To cite this article:}

Sisay Bissa Jima, Tomas Benti Tefera, Muktar Beshir Ahmed. Prevalence of Tobacco Consumption, Alcohol, Khat (Catha Edulis) Use and High Blood Pressure among Adults In Jimma Town, South West Ethiopia. Science Journal of Public Health. Vol. 3, No. 5, 2015 , pp. $650-654$. doi: $10.11648 /$ j.sjph.20150305.19

\begin{abstract}
Introduction Use of substances such as alcohol, khat leaves (Catha edulis) and tobacco has become one of the rising major public health and socio-economic problems worldwide. Recent trends indicate that the use of substances have dramatically increased particularly in developing countries. The prevalence of CVDs and other chronic diseases is growing more rapidly in developing countries. Hypertension is a growing public health problem and about $19.1 \%$ of adults had Hypertension. Methods A community based cross-sectional descriptive study design was employed. A semi structured questionnaire was used to assess association of tobacco, alcohol and Khat (Catha edulis) use with high blood pressure among adults in jimma town, south west Ethiopia. Prevalence of cigarette smoking, alcohol drinking, and khat (Catha edulis ) chewing was determined. Blood pressure was measured three times for each individuals using OmronHEM-711DLX Automatic Blood pressure monitor and the average was used to categorize the subjects into hypertensive and non hypertensive. Results Prevalence of Tobacco uses, drinking alcohol, and chewing khat were, 150(35.5\%), 202(50\%), 289(68.5\%) respectively. The Prevalence of high blood pressure was 79 (18.7\%). Tobacco consumption, alcohol drinking, age group of 5059 and sex were significantly associated with high blood pressure among adults of the town. Conclusion The magnitude of risk factors for hypertension is considerably high in the study population. Roughly one five adults in this study area had high blood pressure. Cigarette smoking, alcohol drinking, chewing khat was associated with high blood pressure. These findings are crucial for evidence based decision making. It will help policy makers for planning of preventive and control measures of these modifiable risk factors. This study will also give baseline information that will enable researchers to conduct longitudinal studies.
\end{abstract}

Keywords: Substance Use, High Blood Pressure, Tobacco Use, Khat Use, Tobacco Smoking, Alcohol

\section{Introduction}

Use of substances such as alcohol, khat leaves (Catha edulis) and tobacco has become one of the rising major public health and socio-economic problems worldwide. Recent trends indicate that the use of substances have dramatically increased particularly in developing countries [1]. The prevalence of CVDs and other chronic diseases is growing worldwide but more rapidly in developing countries [2]. Hypertension is a growing public health problem, with remarkable contribution to cardiovascular diseases (CVD) morbidity. Worldwide, an estimated 1 billion individuals have hypertension, and approximately 7.1 million deaths per year are attributable to hypertension [3]. It is estimated that more than 20 million people are affected in the African Region, where prevalence ranges from 25 percent to 35 percent in adults aged 25 to 64 years (4). In Ethiopia, The overall prevalence of hypertension was $19.1 \%$ of which $22 \%$ were men and $14.9 \%$ were women [5].

Different risk factors are contributing to high burden of non communicable diseases. Of these risk factors tobacco is the fourth most common risk factor for the diseases and the second major cause of death worldwide and currently responsible for the death of one in ten adults worldwide [6]. Alcohol consumption is also the leading risk factors for the disease burden and mortality in low developing countries and 
the third largest risk factor in developing countries [7].

Khat is found in the flowering evergreen tree or large shrub of Celastraceous family. It consists of whole fresh leaves and buds of a plant known as Catha edulis. It is indigenous to Ethiopia, Kenya, and Yemen [8].

More than 20 different compounds including, Cathinone/amino propiophenone/, Cathine/nor pseudoephedrine/and nor ephedrine have been isolated from Khat [9]. Regular and repeated intake of Khat has recently been reported to be associated with increased risk of high blood pressure [10]. The main objective of this study was to address the association between selected substance uses (tobacco consumption, alcohol drinking and khat chewing) and increased blood pressure or hypertension. Having data on these selected substance uses are very important for designing prevention programs which has a paramount importance in reduction of chronic diseases and other diseases occurring as a consequences of substance uses.

\section{Methods and Material}

The study was conducted in Jimma Town from February 30 to April 30, 2012. Jimma town is located $354 \mathrm{KM}$ to South West of Addis Ababa. Based on figures from the Central Statistical Agency in 2007 Ethiopia (CSA), this town has a total population of 120,960 . The town has one specialized Hospital, 2 health centres, and 2 health posts.

A community based cross-sectional study design was employed. Eight Kebeles out of 13 Kebeles were selected by lottery method and subsequent households were selected using systematic random sampling. The total sample size of 422 was distributed among selected kebele proportionally. One adult age between 18 and 65 years old was chosen by lottery method for interview from the selected households.

For data collection, a semi-structured questionnaire, modified from the World Health Organization instrument for stepwise surveillance (WHO STEPS) of chronic disease risk factors[11] was used. The questionnaire was pretested and translated from English to Afaan Oromo (Local Language) and back to English for consistency.

Intensive training was given for data collectors on the purposes of the study, sample selection, interview methods, and measuring blood pressure and how to get informed consent from study subjects. Interview method was used to collect data on socio demographic part of the tool and substances uses.

Three consecutive measurements of BP were taken on the left arm at 3-5 minutes interval using OmronHEM-711DLX Automatic Blood pressure monitor. Average of the measurement was used to describe the mean systolic blood pressure (SBP) and mean diastolic blood pressure (DBP) of study participants.

Those adults having mean SBP $\geq 140$ and/ or DBP $\geq 90 \mathrm{mmHg}$ were classified as hypertensive and those having SBP $<90 \mathrm{mmHg}$ and/or DBP $<140 \mathrm{mmHg}$ as non hypertensive as per world health organization.

Data were analysed using SPSS version 19. Both descriptive and summary measures were used. Multiple logistic regression (MLR), employed to find out independent predictors of High blood pressure/hypertension, with Odds ratios (OR) at $95 \%$ confidence intervals. Statistical significance was declared at $\mathrm{P}$ value of $<5 \%$.

Ethical approval was obtained from the Ethical Board of Jimma University. Also permission was obtained from the town Administrative offices and each selected kebeles. Informed consent was obtained from study participants to undertake the interview and blood pressure measurement. Ethical conduct was maintained throughout the research process.

\section{Results}

A total of 422 adults were interviewed, yielding response rate of $100 \%$. Among the 422 study participants, $29.4 \%$ were females and $70.6 \%$ were males. Forty two $(10 \%)$ of them were illiterate, majority were Oromo in ethnicity and Muslim in religion. Mean age was $41.7(\mathrm{SD}, 10.5)$ years (Table 1).

Table 1. Distribution of socio-demographic characteristics of the study participants in Jimma, South West, Ethiopia, Feb - April, 2012(n=422).

\begin{tabular}{|c|c|c|}
\hline Variables & Frequency & Percentage \\
\hline \multicolumn{3}{|l|}{ Sex } \\
\hline Male & 298 & 70.6 \\
\hline Female & 124 & 29.4 \\
\hline \multicolumn{3}{|l|}{ Education status } \\
\hline Illiterate & 42 & 10.0 \\
\hline Primary complete & 145 & 34.4 \\
\hline Secondary complete & 107 & 25.4 \\
\hline Colleges and above & 128 & 30.2 \\
\hline \multicolumn{3}{|l|}{ Ethnicity } \\
\hline Oromo & 245 & 58.0 \\
\hline Dawuro & 37 & 8.8 \\
\hline Amara & 42 & 10.0 \\
\hline Kefa & 38 & 9.0 \\
\hline Yem & 21 & 5.0 \\
\hline Gurage & 39 & 9.2 \\
\hline \multicolumn{3}{|l|}{ Religion } \\
\hline Christian & 176 & 41.7 \\
\hline Muslim & 246 & 58.3 \\
\hline \multicolumn{3}{|l|}{ Age } \\
\hline $20-29$ & 227 & 53.8 \\
\hline $30-39$ & 109 & 25.8 \\
\hline $40-49$ & 40 & 9.5 \\
\hline $50-59$ & 30 & 7.1 \\
\hline 60 and above & 16 & 3.8 \\
\hline \multicolumn{3}{|l|}{ Occupation } \\
\hline Governmental employee & 87 & 20.6 \\
\hline Daily laborer & 118 & 28.0 \\
\hline Merchant & 73 & 17.3 \\
\hline Student & 80 & 19.0 \\
\hline $\begin{array}{l}\text { Nongovernmental } \\
\text { employee }\end{array}$ & 27 & 6.4 \\
\hline House wife & 24 & 5.7 \\
\hline Pensioner & 7 & 1.6 \\
\hline Farmer & 6 & 1.4 \\
\hline
\end{tabular}

Prevalence of hypertension among the adults were about 79(18.7\%) based on blood pressure measurement. About Thirty five percent of the study subjects reported current tobacco smoking. Median age at start of smoking was 24 
years (range, $14-52$ years) (SD, 5.1).

About sixty eight percent of study subjects reported current khat chewing. Ninety Eight $(33.9 \%)$ of the study subjects chewed khat every days, $63(21.8 \%)$ chewed khat 23 days per week. Two hundred two $(49.7 \%)$ of study subjects, reported current alcohol consumption (drinking within the preceding 12 months). About ten percent reported daily alcohol use and twenty seven percent reported drinking alcohol less than one to four Days per week (Table 2).

Table 2. Prevalence of hypertension based on blood pressure measurement among adults of jimma town, south west Ethiopia Feb - April, 2012(n=422).

\begin{tabular}{lll}
\hline Hypertension status & Frequency & Percentage \\
\hline Hypertensive & 79 & 18.7 \\
Not hypertensive & 343 & 81.3 \\
\hline
\end{tabular}

Mean systolic BP was $122.79 \mathrm{~mm} \mathrm{Hg}$ and the mean diastolic pressure was $77.47 \mathrm{~mm} \mathrm{Hg}$ for the study subjects. The prevalence of hypertension or increased blood pressure was about $79(18.7 \%$ ) (Table 3$)$.

Subjects who were not using tobacco were less likely to develop hypertension compared to tobacco users (AOR: 0.34, 95\%CI: 0.18-0.70). Subjects who were not drinking alcohol currently were less likely to develop hypertension compared to currently drinking alcohol (AOR: $0.28,95 \%$ CI: $0.14-0.57$ ) (Table 4).

Table 3. Distribution of substance use among study subjects of jimma town, South West, Ethiopia, Feb - April, 2012(n=422).

\begin{tabular}{|c|c|c|}
\hline Variables & Frequency & Percentage \\
\hline \multicolumn{3}{|c|}{ Tobacco consumption } \\
\hline Yes & 150 & 35.5 \\
\hline No & 272 & 64.5 \\
\hline \multicolumn{3}{|c|}{ Currently smokers } \\
\hline Yes & 150 & 35.5 \\
\hline No & 272 & 64.5 \\
\hline \multicolumn{3}{|c|}{ Alcohol consumption } \\
\hline Yes & 211 & 50.0 \\
\hline No & 211 & 50.0 \\
\hline \multicolumn{3}{|c|}{ Used Alcohol within past 12 months } \\
\hline Yes & 202 & 47.9 \\
\hline No & 220 & 52.1 \\
\hline \multicolumn{3}{|c|}{ Frequency of Alcohol uses } \\
\hline Daily & 21 & 10.2 \\
\hline 5-6days/week & 43 & 21.0 \\
\hline 1-4days/week & 56 & 27.3 \\
\hline 1-3days/week & 41 & 20.0 \\
\hline$<1$ days/week & 44 & 21.5 \\
\hline \multicolumn{3}{|l|}{ Chew chat ever } \\
\hline Yes & 289 & 68.5 \\
\hline No & 133 & 31.5 \\
\hline \multicolumn{3}{|c|}{ Khat+Alcohol+Tobacco uses } \\
\hline Yes & 99 & 76.5 \\
\hline No & 323 & 23.5 \\
\hline
\end{tabular}

Table 4. Multivariable analysis for hypertension based on blood pressure measurement among study subjects of jimma town, south east Ethiopia, Feb - April, 2012( $n=422), 2012(n=422)$.

\begin{tabular}{lll}
\hline Variables & Frequency & AOR(95\%CI) \\
\hline Tobacco & & \\
No & 272 & $0.34(0.17-0.70)$ \\
Yes & 150 & ref \\
Alcohol & & \\
No & 211 & $0.28(0.14-0.57)$ \\
Yes & 211 & ref \\
Chew chat ever & & \\
No & 133 & $0.57(0.27-0.52)$ \\
Yes & 289 & ref \\
Religion & & \\
Christian & 176 & $0.73(0.37-1.45)$ \\
Muslim & 246 & ref \\
Educational status & & \\
Illiterate & 42 & $2.38(0.86-6.64)$ \\
Primary & 145 & $0.83(0.38-1.82)$ \\
Secondary & 107 & $0.09(0.44-0.18)$ \\
College & & ref \\
Sex & 42 & \\
Male & & $0.36(0.16-0.79)$ \\
Female & 124 & ref \\
Age & 298 & \\
$20-29$ & & $0.28(0.07-1.02)$ \\
$30-39$ & 227 & $0.38(0.10-1.45)$ \\
$40-49$ & 109 & $1.47(0.36-6.05)$ \\
$50-59$ & 40 & $4.87(1.12-21.24)$ \\
$60^{+}$ & 30 & ref \\
\hline
\end{tabular}

AOR $=$ Adjusted Odd Ratio, $\mathrm{CI}=$ Confidence Interval

\section{Discussion}

Epidemiological transition has resulted in double burden of communicable and non communicable disease in most developing countries. Most of these diseases share risk factors like tobacco use, alcohol consumption and khat chewing. This study also examined association of substance use with increased blood pressure in the adult population of jimma town. Tobacco consumption is the second major cause of death in the world. This study revealed that Prevalence of tobacco consumption among study subjects was about $35.5 \%$ which is higher than the prevalence of smoking among adults in Butajira, Southern Ethiopia which was 5.8\% [12] and Finding from Gilgel Gibe Field Research Center, Jimma [13]. This indicates that considerable proportion of the community was smoking that puts them at higher risk for chronic Non communicable Diseases.

The study conducted in rural part of Iraq reported that all most all current smokers were daily smokers [14] which are consistent with this study finding. In this study, Adults who were not experienced tobacco consumption were less likely to develop hypertension compared to those experienced tobacco consumption which is consistent with finding from the study conducted among adults in Addis Ababa [15]. The possible reason for this is due to the fact that smoking causes an acute increase in arterial stiffness and associated with greater endothelial dysfunction which results in High blood pressure [16].

High risk alcohol use was related to different chronic 
diseases like cardio vascular diseases [17]. This study revealed that Alcohol drinking was significantly associated with increased blood pressure or hypertension. The prevalence of alcohol consumption was $50 \%$ which is higher than the finding from Haramaya University (41.7\%) [18], Gilgel Gibe Field Research Center (7.3\%)[13)], and lower than finding from Iringa of Tanzania (71\%) [19]. Possible explanation for these differences would be due to sample size, socio cultural and study setting differences.

The current prevalence of khat chewing (68.5\%) is higher than the finding in Butajira, Ethiopia [20], Gilgel Gibe Field Research Center, Bahir Dar town (19.6\%)[13] and findings of other studies in Ethiopia [21, 22, 23]. The difference could be due to difference in study setting, cultural and the study populations. This Study also found that chat chewing has significant association with increased blood pressure. The possible reason might be due to the effects of amphetamine on blood vessels.

In this study, the prevalence of high blood pressure was found $18.7 \%$ which is similar with finding from Sidama Zone, Ethiopia (18.8\%)[24], and higher than the finding from, Gilgel Gibe Field Research Center,Jimma (9.3\%)[13], Eritrea $(10.3 \%)[25]$ and Nigeria (16\%)[26] And lower than finding from Durame Town, Southern Ethiopia (22.4\%)[27]. This discrepancy could be due to difference in study setting, socio cultural differences and time of the study.

\section{Conclusion}

The magnitude of risk factors for hypertension is considerably high in the study population. Roughly one five adults in this study area had high blood pressure. Cigarette smoking, alcohol drinking, chewing khat was associated with high blood pressure. These findings are crucial for evidence based decision making. It will help policy makers for planning of preventive and control measures of these modifiable risk factors. This study will also give baseline information that will enable researchers to conduct longitudinal studies.

\section{Acknowledgements}

We would like to acknowledge College of Medicine and Health Sciences of Jimma University for giving grant for this study. We gratefully acknowledge study participants who enthusiastically participated in this study for their time and patience during data collection.

\section{Author Contributions}

Sisay Bissa: conceives the study, contributed to the design of the questionnaire and data analysis.

Tomas Benti: Contributed to data analysis and manuscript preparation and final approval of the Manuscript.

Muktar Beshir: Involved in data analysis and critically reviewed the manuscript

\section{References}

[1] Odejide AO. Status of drug use/abuse in Africa: A review. International journal of Mental Health ,2006; 4:87-102.

[2] Joshi R, Cardona M, Iyengar S, Sukumar A, Raju CR, Raju $\mathrm{KR}$, et al. Chronic diseases now a leading cause of death in rural India - mortality data from the Andhra Pradesh Rural Heath Initiative. Int J Epidemiol, 2006; 35(6):1522-9.

[3] Kearney PM, Whelton M, Reynolds K, Munter P, Whelton PK, He J. Global burden of hypertension: analysis of worldwide data. Lancet, 2005; 365:217-23.

[4] WHO AFRO. Cardiovascular diseases in the African Region: Current Situation and Perspectives. Report of the Regional Director. Fifty-fifth sessions. Maputo, Mozambique 2005.

[5] Nshisso LD, Reese A, Gelaye B, Lemma S, Berhane Y, Williams MA. Prevalence of hypertension and diabetes among Ethiopian adults. Diabetes Metab Syndr. 2012; 6(1):36-41

[6] WHO. The world health report: reducing risk, promoting health life, Geneva. WHO, 2002.

[7] WHO. Global Status Report on Alcohol. Geneva, Switzerland, World Health Organization, 2004.

[8] Al-Hebshi N, Skaug N. Khat (Catha edulis) - an updated reviews. Addiction Biol, 2005; 10:299-307.

[9] Kalix P. Pharmacological properties of the stimulant Khat research. Clin Pharmacol Ther, 1990; 48:397-416.

[10] Kebede D, Alem A, Mitikie G, Enquselassie F, Berhane F, Abebe Y, et al. Khat and alcohol use and risky sex behavior among in-school and out-of-school youth in Ethiopia. BMC Public Health , 2005; 5:109-114.

[11] World Health Organization, author. Chronic diseases and health promotion. STEPwise approach to surveillance (STEPS) STEPS Manual. [December 2005]. Available at: http://www..who.int/chp/steps.

[12] Neil's Schoenmaker, Jeroen Hermanides, and Gail Davey. Prevalence and predictors of smoking in Butajira town, Ethiopia. Ethiop J Health Dev, 2005; 19(3):182-187.

[13] Yeshalem Mulugeta. Khat Chewing and Its Associated Factor among College Students in Bahir Dar Town, Ethiopia. Science Journal of Public Health. Vol. 1, No. 5, 2013, pp. 209214.WHO.

[14] Chronic Non communicable Diseases Risk factors Survey in Iraq in collaboration with World Health Organization. A STEP wise approach 2006.

[15] Tesfaye F, Byass P, Berhane Y, Bonita R, Wall S. Association of smoking and khat (Catha edulis Forsk) use with high blood pressure among adults in Addis Ababa, Ethiopia. Prev Chronic Dis, 2008; 5(3).

[16] Karatzi K, Papamichael C, Karatzis E, et al. Acute smokeinduced endothelial dysfunction is more prolonged in smokers than in non-smokers. Intern J Cardio. 2007; 120: 404-406.

[17] WHO Global Report on Alcohol 2004. 
[18] Andualem Derese, Assefa Seme, Chalachew Misganaw. Assessment of Substance Use and Risky Sexual Behaviour among Haramaya University Students, Ethiopia. Science Journal of Public Health. Vol. 2, No. 2, 2014, pp. 102-110.

[19] Mghamba J, Senkoro K, Semu H , Mohamed M , Mmbuji P: Risk factors for non communicable diseases among semirural adults and the association of these factors with socio demographic variables: findings from the who steps survey in Kilolo district, Iringa, Tanzania, 2007

[20] Tesfaye F. Epidemiology of Cardiovascular Risk Factors in Ethiopia: The Rural-Urban Gradient.Sweden: Umea University; 2008.

[21] Eshetu E, Gedif T. Prevalence of Khat, cigarette and alcohol use among students of Technology and Pharmacy, Addis Ababa University. Ethioipian Pharmaceutical Journal. 2006;24(2):116-124.

[22] Kebede Y. Cigarette smoking and khat chewing among college students in Northwest Ethiopia. Ethiopian Journal of Health Development. 2002;16(1):9-17.
[23] Gelaw Y, Haile-Amlak A. Khat Chewing and its Sociodemographic Correlates among the staff of Jimma University. Ethiopian Jouranl of Health Development. 2004;18(3):179184.

[24] Giday A, Tadesse B (2011) Prevalence and determinants of hypertension in rural and urban areas of southern Ethiopia. Ethiop Med J 49 (2):139-147

[25] Mufunda J, Mebrahtu G, Usman A, Nyarango P, Kosia A, et al. (2006) The prevalence of hypertension and its relationship with obesity: results from a national blood pressure survey in Eritrea. Journal of Human Hypertension 20:59-65.

[26] Olatunbosun ST, Kaufman JS, Cooper RS, Bella AF (2000) Hypertension in a black population: prevalence and biosocial determinants of high blood pressure in a group of urban Nigerians. J Hum Hypertens 14 (4):249-57.

[27] Helelo TP, Gelaw YA, Adane AA (2014) Prevalence and Associated Factors of Hypertension among Adults in Durame Town, Southern Ethiopia. PLoS ONE 9(11). 